\title{
Project Panopia: cost-effective model for glaucoma referral refinement from community optometrists without the need for repeat testing
}

\author{
Rashmi G. Mathew $\mathbb{1}^{1} \cdot$ Connor J. Beddow ${ }^{1} \cdot$ Hayley Raison ${ }^{1} \cdot$ Dawn A. Sim (i) ${ }^{1}$
}

Received: 2 July 2020 / Revised: 21 July 2020 / Accepted: 5 August 2020

(c) The Author(s) 2020. This article is published with open access

\section{The context}

The quality and productivity gains that we seek lie at the heart of primary and secondary healthcare interface [1]. In the context of glaucoma, this involves referrals from community optometrists where there is currently a $40 \%$ false-positive rate (England, UK) [2, 3]. Multiple reports have shown that referral refinement has the potential to work [4-6]. One refinement scheme demonstrated up to $89 \%$ of glaucoma referrals could be kept out of Hospital Eye Service [HES] when Humphrey visual fields, Goldmann applanation tonometry and disc imaging were included [6]. Despite this, the cost-effectiveness of such schemes remains to be proven, largely due to the requirement of repeat testing within such pathways.

With the success of referral refinement programmes over the past two decades, why have these programmes been unable to scale? Interoperability of software platforms is a key barrier at the interface of primary and secondary care, and a priority area for the National Health Service (NHS) England [7]. Healthcare interoperability is hindered by data stored on heterogeneous proprietary legacy systems, which prevents interoperability with other vendor applications and protects market share [8].

\section{Ideals, intervention and causal assumptions}

\section{Ideals}

Telemedicine advocates the conceptualisation of the desired future state first, before finding the right technology to suit

Rashmi G. Mathew

Rashmi.mathew1@nhs.net

1 Moorfields Eye Hospital NHSFT, London EC1V 2PD, UK the workflow [9]. We extended this ideal to managing glaucoma by creating a two-way feedback mechanism between primary and secondary care and providing a onestop service for patients close to home, with resultant improved access to secondary care within a cost-effective pathway.

\section{Intervention}

A direct glaucoma pathway was set up between community optometrists and HES in order to provide a remote review service. The pathway bypassed current barriers of interoperability by utilising 'nhs.net' mail as an interim technology to facilitate the transfer of information. Requisite to the pathway was the provision of complete datasets by community optometrists. We called our model Panopia, to symbolise a concept where we take 'a whole view of the referral pathway'.

\section{Causal assumptions}

The causal assumptions underpinning the intervention being that remote oversight of referrals would reduce false positives to HES without the need for repeat testing, and consistent feedback would improve the quality of the referrals.

\section{Methods}

A feasibility study utilising the new pathway was undertaken with 20 referrals. The primary aims, secondary aims and remote decisions of the feasibility study are listed in Table 1. Prior to the commencement of Panopia, we engaged stakeholders, which included Newham clinical commissioning group [CCG], local general practitioners and the local optometrists. An enhanced optometric tariff of $£ 46$ for each referral was agreed. 


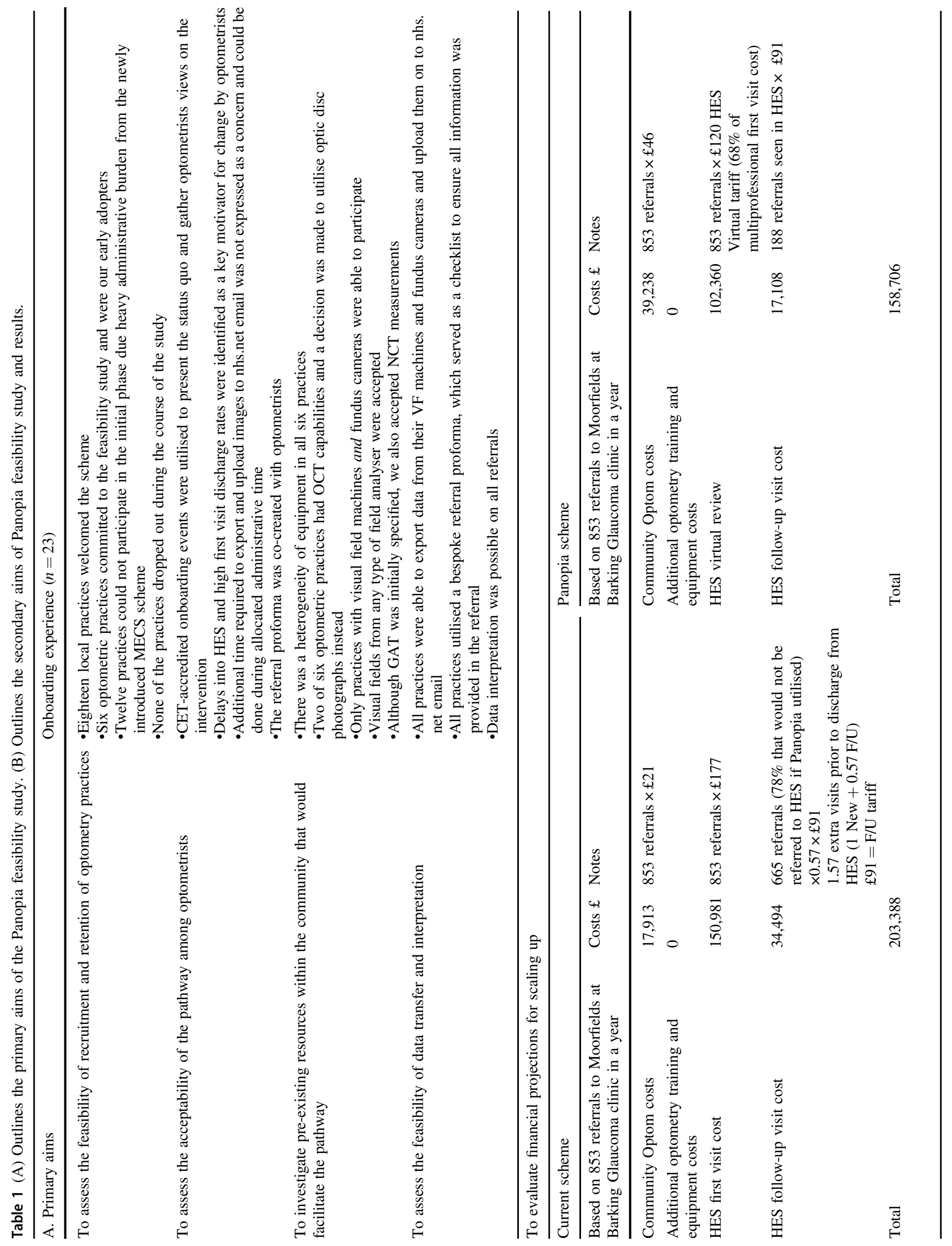




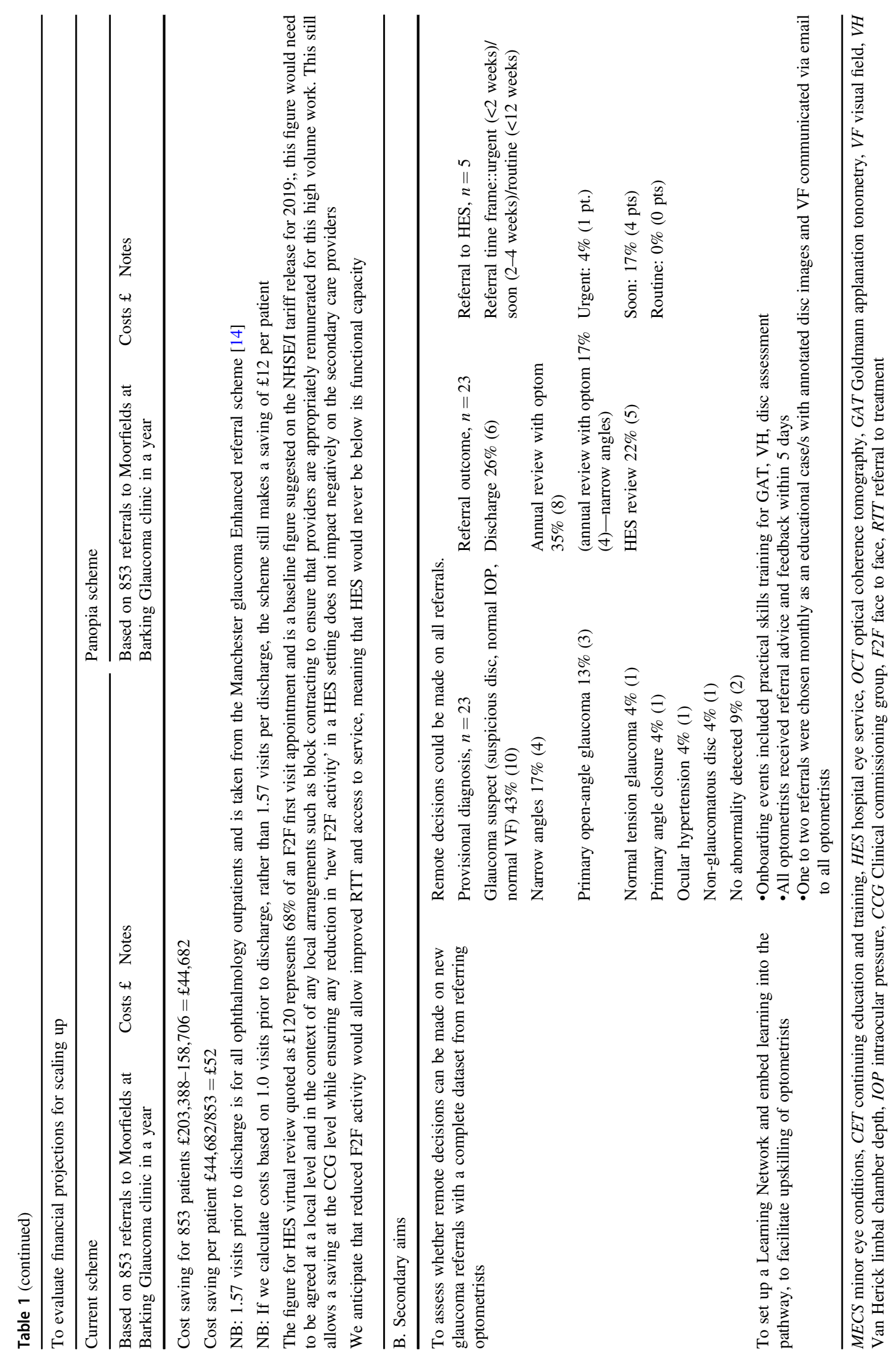


A complete dataset in an optometry referral included demographic details, reason for referral, family history of glaucoma, visual acuity, refraction, intraocular pressure (non-contact tonometry [NCT] or Goldmann applanation tonometry), Van Herick limbal chamber depth grade [VH], images of disc photographs, images of visual fields (any field type). A bespoke referral proforma was used. Optic disc photos and visual fields were transferred using nhs.net email. NHS.net email is automatically encrypted and complies with pan-government secure email standard and is therefore suitable for sharing patient sensitive information.

Feedback on each referral was sent to the referring optometrist within 5 days using nhs.net email. This work was registered with the Service Improvement Department of Moorfields Eye Hospital and complies with the criteria defined in the Declaration of Helsinki.

\section{Comment}

Panopia was launched with a view to improve the current glaucoma referral model and to symbolise a concept whereby 'a whole view of the new glaucoma patient pathway' is taken.

Like any incremental innovation, feasibility studies are important to assess the processes involved and anticipate unforeseen difficulties. In this paper, we outline the key steps in order to initiate a new pathway, the change management required for implementation and undertook financial modelling to assess cost-effectiveness. As with any complex intervention, tailoring of the scheme was needed from the outset to suit the local context [10].

In this feasibility study, we demonstrated that we were able to deliver this scheme with high fidelity to the originally intended proposal. A total of 23 new glaucoma referrals were received between July and December 2019. The mean age of the cohort was $49 \pm 13$ years (range: 20-69). Forty-five per cent were female. Mean bestcorrected visual acuity was $-0.02 \mathrm{RE}$ and $-0.01 \mathrm{LE}$, and mean intraocular pressure was $18 \mathrm{mmHg}$ (range 9-39 $\mathrm{mmHg}$ ). A provisional diagnosis was made on $100 \%$ of referrals (see Table 1), with the most common reason for referral being suspicious optic discs (43\%), highlighting the importance of disc imaging. Between 61 and $78 \%$ of referrals could be kept out of HES, depending on the risk threshold set.

Utilisation of existing optometry equipment without repeat testing was unique to the model and represented a paradigm shift in glaucoma referral refinement pathways. Equipment heterogeneity and ingrained use of NCT were important considerations, and decision making based on community-acquired data has been historically hindered by these factors. Integral to the scheme and decision making was the provision of a complete dataset by the optometrist for remote assessment by an ophthalmologist in HES.

'Repeat measures', 'enhanced case finding' and 'referral refinement' filtration schemes have already been in existence for more than two decades and often involve a second visit for the patient to repeat tests with standard equipment. In 1997, an audit of false-positive glaucoma referrals to HES, found they were discharged after 2.3 visits [11, 12]. A figure of over two visits has been incorporated into financial modelling for many referral filtering schemes [4, 12, 13]. It has since been refined in 2019 by the Manchester Glaucoma Enhanced referral scheme, which observed that the figure was reduced to $1.57 \mathrm{HES}$ visits prior to discharge for all ophthalmic subspecialities [14], challenging the cost-effectiveness of existing filtering schemes. Using this more conservative estimate, the cost savings of our model were $£ 52$ (1.57 HES visits) and $£ 12$ per patient (1.0 HES visits) (see Table 1).

Another unique feature of the scheme is the Panopia Learning Network, which engaged individual optometrists with personalised feedback, such as annotations on disc images and bidirectional dialogue, with an end goal of improving referral quality.

Patient experience and safety must be at the heart of any healthcare change. Panopia is a proof of concept that this model provides a vehicle for expedited diagnosis, communication with patients and review in HES. It further reduces the anxiety associated with long waits ( 5 months from the time of optometry referral to diagnosis, R.G. Mathew, personal communication) and has the potential to improve patient safety from delayed appointments [15].

Panopia was conceived with the vision for a future model of glaucoma care. We applied an incremental change to enable stakeholder acceptance of both new pathways and technology. Human-technology interactions are likely to play a key role in the success of such pathways, and feasibility studies like these are important for scalability. In our scheme up to $78 \%$ of referrals could be kept out of HES by acquiring a minimum dataset transferred via secure email and with a cost saving of $£ 52$ per patient. Embracing technology that automates data acquisition and a transfer would allow scaling of this model and boost 'out-of-hospital' care as envisaged by the NHS Long-Term Plan [16].

\section{Summary}

\section{What was known before}

- There is at least a $40 \%$ false-positive rate for glaucoma referrals seen in HES.

- This delays appointments for those with true pathology.

- Current filtration schemes show variable costeffectiveness. 


\section{What this study adds}

- This pilot of a remote review of glaucoma referrals with complete datasets from community optometrists showed that $78 \%$ of referrals could be kept out of HES, with a potential cost saving of $£ 52$ per patient.

\section{How might these results influence clinical practice}

- Scaling up of this model with technology that automates data acquisition and transfer would significantly boost 'out-of-hospital' care.

Acknowledgements We would like to acknowledge the following people for their contributions towards the project. Anna Majkowska, Service Improvement Manager, Moorfields Eye Hospital, who has been instrumental in helping to set up the scheme; Nasreen Munshi, Optometrist at Eye Emporium Stratford; Ash Patel, Ex-director of Specsavers Stratford; Mohammed Rehmani, Director of Specsavers Ilford; Aratope Ajose, Optometrist at Specsavers Stratford; Sanjiv Sharma, Director of Specsavers, East Ham and Beckton branches, for their enthusiasm for Project Panopia and referrals into the scheme.

Funding Open access to this article is funded by Moorfields Eye Charity [GR001241].

\section{Compliance with ethical standards}

Conflict of interest The authors declare that they have no conflict of interest.

Publisher's note Springer Nature remains neutral with regard to jurisdictional claims in published maps and institutional affiliations.

Open Access This article is licensed under a Creative Commons Attribution 4.0 International License, which permits use, sharing, adaptation, distribution and reproduction in any medium or format, as long as you give appropriate credit to the original author(s) and the source, provide a link to the Creative Commons license, and indicate if changes were made. The images or other third party material in this article are included in the article's Creative Commons license, unless indicated otherwise in a credit line to the material. If material is not included in the article's Creative Commons license and your intended use is not permitted by statutory regulation or exceeds the permitted use, you will need to obtain permission directly from the copyright holder. To view a copy of this license, visit http://creativecommons. org/licenses/by/4.0/.

\section{References}

1. Nicholson D. Implementing the next stage review visions: the quality and productivity challenge. Letter 10 August 2009, Gateway ref: 12396.

2. Bowling B, Chen SD, Salmon JF. Outcomes of referrals by community optometrists to a hospital glaucoma service. $\mathrm{Br} \mathrm{J}$ Ophthalmol. 2005;89:1102-4.

3. Founti P, Topouzis F, Hollo G, Cvenkel B, Iester M, Haidich A, et al. Prospective study of glaucoma referrals across Europe: are we using resources wisely? Br J Ophthalmol. 2018;102:329-37.

4. Ratnarajan G, Newsom W, French K, Kean J, Chang L, Parker M, et al. The impact of glaucoma referral refinement criteria on referral to, and first-visit discharge rates from, the Hospital Eye Service: The Health Innovation \& Education Cluster (HIEC) Glaucoma Pathways Project. Ophthalmic Physiol Opt. 2013;33:183-9.

5. Bourne RRA, French KA, Chang L, Borman AD, Hingorani M, Newsom WD. Can a community optometrist-based referral refinement scheme reduce false-positive glaucoma hospital referrals without compromising quality of care? The Community and Hospital Allied Network Glaucoma Evaluation Scheme (CHANGES). Eye. 2010;24:881-87.

6. Trikha S, Macgregor C, Jeffery M, Kirwan J. The Portsmouthbased glaucoma refinement scheme: a role for virtual clinics in the future?. Eye. 2012;26:1288-94.

7. Heubusch K. Interoperability: what it means, why it matters. J AHIMA. 2006;77:26-30. quiz 33-34

8. Olaronke I, Oluwaseun O. Big data in healthcare: Prospects, challenges and resolutions. 2016 Future Technologies Conference (FTC), San Francisco, CA; 2016. pp. 1152-57. https://doi.org/10. 1109/FTC.2016.7821747.

9. Saleem SM, Pasquale LR, Sidoti PA, Tsai JC. Virtual ophthalmology: telemedicine in a Covid-19 era. Am J Ophthalmol. 2020. https://doi.org/10.1016/j.ajo.2020.04.029.

10. Orsmond GI, Cohn ES. The distinctive features of a feasibility study: objectives and guiding questions. OTJR. 2015;35:169-77. https://doi.org/10.1177/1539449215578649.

11. Henson DB, Spencer AF, Harper R, Cadman EJ. Community refinement of glaucoma referrals. Eye . 2003;17:21-6.

12. Devarajan N, Williams GS, Hopes M, O'Sullivan D, Jones D. The Carmarthenshire Glaucoma Referral Refinement Scheme, a safe and efficient screening service. Eye. 2011;25:43-9.

13. Parkins DJ, Edgar DF. Comparison of the effectiveness of two enhanced glaucoma referral schemes. Ophthalmic Physiol Opt. 2011;31:343-52.

14. Forbes H, Sutton M, Edgare DF, et al. Impact of the Manchester Glaucoma Enhanced Referral Scheme on NHS costs. BMJ Open Ophthalmol. 2019;4:e00278.

15. Foot B, MacEwen C. Surveillance of sight loss due to delay in ophthalmic treatment or review: frequency, cause and outcome. Eye. 2017;31:771-5.

16. NHS England. NHS Long Term Plan. 2019. https://www. longtermplan.nhs.uk/. Accessed 22 Jun 2020. 